\title{
Design and Development of a Life Insurance Mobile Application for Young Adults
}

\author{
FAISAL ADLI BIN TAJUL ANUAR \& CHEE SIONG TEH*
}

\author{
Faculty of Cognitive Sciences and Human Development, Universiti Malaysia Sarawak, 94300 Kota Samarahan, \\ Sarawak, Malaysia \\ *Corresponding authors: csteh@unimas.my
}

\begin{abstract}
In this modern era, accidents could occur anywhere any time before prevention can be made. Life insurance could help lend a sum of money to reimburse the medical fees. But not everyone has life insurance, some people think that life insurance is a waste of money where they think people should save money at an early age and only pay when an actual accident occurs. This occurs in young adults too. Some young adults do not know the knowledge of life insurance. Therefore, this study is conducted to help young adults understand and provide the awareness of the importance of life insurance by creating a mobile application on Android Operating System using Android Studio. This system was created based on waterfall system development life cycle and evaluated using cooperative evaluation method. The mobile application can display and provide the knowledge of life insurance and calculate the suggested life insurance plan for the user. Five participants were randomly selected for cooperative evaluation. They are young adults age between 20 to 25 years old and have their own income. Out of those five participants, two of them like the mobile application while the other three participants suggested several improvements on the developed mobile application.
\end{abstract}

Keyword: Life insurance, mobile application, young adults

Copyright: This is an open access article distributed under the terms of the CC-BY-NC-SA (Creative Commons Attribution-NonCommercial-ShareAlike 4.0 International License) which permits unrestricted use, distribution, and reproduction in any medium, for non-commercial purposes, provided the original work of the author(s) is properly cited.

\section{INTRODUCTION}

Life insurance is an agreement between an insurance company with a client. It is a means of financing a person's health care expenses. The life insurance company will absorb the cash value, and your beneficiary will be paid the policy's death benefit (Marquand, 2012). For a set of time, life insurance will give protection to the client but at the same time, permanent insurance will provide a lifetime coverage to the client such as whole and universal life. We will never know when we will need life insurance as accidents come in the most unexpected ways. Payments for a term policy guarantee a specific benefit sum in the event of the client's death while the policy is still active. This means that term coverage works like a "parachute" to cover their family during the years in which an accident could occur (Lant, 2018). When a person is involved in an accident, their responsibilities to dependents will be interrupted. Life insurance can help the victim's family financially. There is broad public support for more government spending on childcare if that spending does not result in another unfunded entitlement that worsens the deficit (Whitehurst, 2017).

People can apply for life insurance from several life insurance company agents. There are many life insurances companies in Malaysia such as Takaful Ikhlas, Prudential and Kurnia Insurance. People can apply by visiting their website, go to their insurance centres or contact their own agents. Some life insurance agents even take the incentive to rent a space in most hospitals, clinics and city halls to promote life insurance to society. Life insurance fee comes in amounts which differ base on factors that will be considered on an application such as personal information, existing savings and insurance, liabilities and expected expenses and desired replacement income. Upon completing this application, the life insurance agent would suggest the amount of life insurance needed to cover any unfortunate events.

There are several problems that arise for young adults insurance coverage. The first is not every young adult in Malaysia have a life insurance plan. Statistically, older adults have a lower drop compared to younger adults in insurance coverage. In the year 2015, there is a drop of 5.6 percent for uninsured 26 years old adults and 1.9 percent drop for uninsured 64 years old adults (Barnett \& Vornovitsky, 2016). The second is young adults do not appear to know which, where and how to apply for life insurance. As most young adults were not introduced to 
life insurance since a younger age, they do not have the ability and capacity to figure out how to purchase a life insurance plan.

Several websites provided guidance on how life insurance work, but the content is too general as the information could be used for all ages. Younger adults need to find the details of life insurance plan that is suitable for their financial and health records. This includes the selection of the best life insurance plan, the amount of fees needed to be paid per month and what is the next step when there are accidents that require them to refer to life insurance that they subscribed. It is very common to see young adults with mobile devices in their hands. Unfortunately, there is no mobile application providing information regarding life insurance. This causes a need for a development of the local-based mobile application.

Hence, this study is to design and develop a life insurance mobile application with repetitive technique to assist young adults and connect them with life insurance, the knowledge of life insurance and the suggested life insurance plan. The insurance company could use the source code provided with the mobile application to customize and improve the mobile application to meet their own needs such as information and details about their life insurance plan. The evaluation conducted from this study can be used as a reference for the future developer on life insurance mobile application that meet the expectation of the young adults.

\section{BACKGROUND}

\section{Importance of Life Insurance to Young Adults}

The economic development of a country in the present-day has a major dependency on the insurance sector as its position in identifying the risk transfer of the community and provider of financial services to the individual and organisation (Ionescu, 2012).

According to Barnett and Vornovitsky (2016), having a regular doctor and receiving recommended preventive care is much likely in young adults that have life insurance coverage. $85 \%$ of insured young adults stated that they have a regular doctor and receive recommended preventive care. But at the same time, only $38 \%$ of them that have no life insurance coverage will do so. Uninsured group suffers in settling the medical bills and those with family can be saddled with thousands of dollars in medical debt caused by catastrophic illness and injury that happened to their family members.

Some young adults avoid or delay when they require medical attention because of the medical cost itself as they do not have full coverage in health insurance. The survey conducted by Barnett and Vornovitsky (2016) showed that the highest score rates of cost-related problems to get needed health care was experienced by uninsured young adults. In ten young adults, six of them were uninsured at the time the survey is conducted and $56 \%$ of them were insured but had been uninsured as there are cost related problems in accessing health care.

\section{Mobile Application}

In the last few years, the use of mobile devices had seen a drastic increase and had become more sophisticated. These devices allow users to accomplish a wide variety of tasks. The number of usability issues has become more prevalent as the result of the ease in the creation and distribution of mobile applications (Flood et al., 2012). The use of a wired information system infrastructure can be reduced with the existence of smartphones and laptop computers. The wireless devices allow tasks to be performed in many different contexts. Good mobility design should be achieved to meet user requirements (Huang, 2009; Gebauer, Tang, \& Baimai, 2008).

The ADDIE model is one of the many popular instructional system design models. It includes five stages which include Analysis, Design, Development, Implementation, and Evaluation (Treser, 2015). There is no specific evaluation that is conducted on life insurance mobile application but there are several evaluations that had been done on various mobile applications. An empirical study based on a set of measures to evaluate the usability of mobile applications (Google Apps and Google Maps) running on different mobile operating systems, including Android, iOS and Symbian is proposed by Moumane, Idri and Abran (2016). The aim of their work is to evaluate empirically a framework that they have developed on the use of the Software Quality Standard ISO 9126 in mobile environments, especially on the usability characteristics. However, for the application developed in this study, a rapid evaluation method is introduced to evaluate the prototype of the developed application before making any changes to the whole design of the life insurance application. Cooperative evaluation method is selected in this study because it is expected to gain the feedback from the user in a short amount of time before a fully operational system is developed. 


\section{Life Insurance in Electronic Version}

Meanwhile, there are only two life insurance mobile applications that had been developed in Malaysia which are 'EZTakaful'(https://www.eztakaful.com.my/) and 'EtiqaHealthCare' (http://www.etiqa.com.my/en/healthcare). For EZTakaful, the mobile application provides information in which users can choose plans they wish to apply. Users can look at plans they wish to purchase and calculate total monthly payment. For EtiqaHealthCare mobile application, the user must apply for the life insurance first before they can have access to the features in the mobile application. Both of these mobile applications do not focus specifically on young adults; it does not highlight the importance of life insurance on insurance buyers especially young adults. The mobile application is more focused on the buying of insurance plan and why that certain plan is good for the client. The mobile application is suitable for post-application insurance policy users as the features provided by the mobile application are focused more on the policy taken and health records. In this study, the knowledge of the life insurance is highlighted to ensure that clients especially young adults can understand the importance of life insurance before making any plan or consideration to buy a life insurance plan.

\section{METHOD}

The System Development Life Cycle (SDLC) method is used in this study. The method includes initial investigation, requirements definition, coding and testing, system design, implementation, and evaluation. This SDLC method is used as a guiding framework because it is ideal for supporting less experienced project teams and project managers, or project teams whose composition fluctuates (Wikipedia, June 2017). Figure 1 shows the phases of the waterfall SDLC.

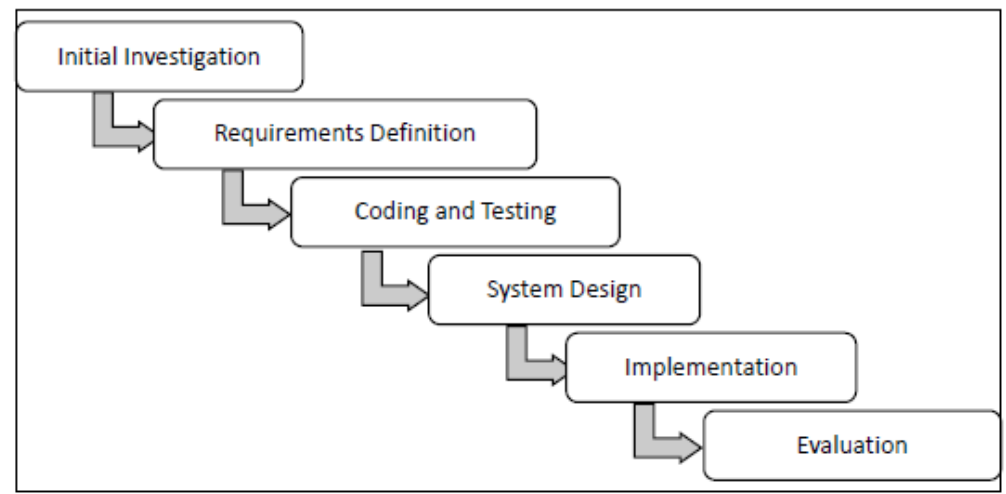

Figure 1. The six stages of Waterfall SDLC model

\section{Initial Investigation}

In the initial investigation phase, all possible items that the system requires are listed such as problems that need to be solved, target audiences and tasks that will be implemented. For the problem that needs to be solved, a research is executed to identify if there is any study on the development of life insurance mobile application. The knowledge related to life insurance and its plan is also searched to be included in the mobile application. For the target audience, the characteristics and other details of the target users are listed to fit the specifications and functions that will be included in the mobile application to solve problems. The task to be implemented is also identified including the task and activities target users will be completing to determine if the solution is suitable for the problem. Several types of research are conducted to find the statistics of the uninsured people which was obtained from the internet and interviews with some life insurance agents.

\section{Requirements}

The requirements definition has been decided after all initial investigation had been done. The mobile application development platform will be Android Studio. This platform is decided based on the difficulties to understand the process of the development. Android studio could easily have adapted to the world of android app development. It is designed particularly for Android development and to accelerate the Android development process. In this phase, some development software has been tried such as Unity before choosing Android Studio as the development software.

\section{Process Flow}

To develop this mobile application system, several processes and flows need to be followed to ensure the system develop smoothly. For this system, the interface for each screen will be created first. This will give the developer a much more visual picture before linking the pages with each other. After all connections between pages are 
established, a simple testing would be done on the software itself before it can be rendered and debugged into an APK file to be installed in an actual mobile phone. This phase will focus on the development flow of the mobile application as seen in Figure 2.

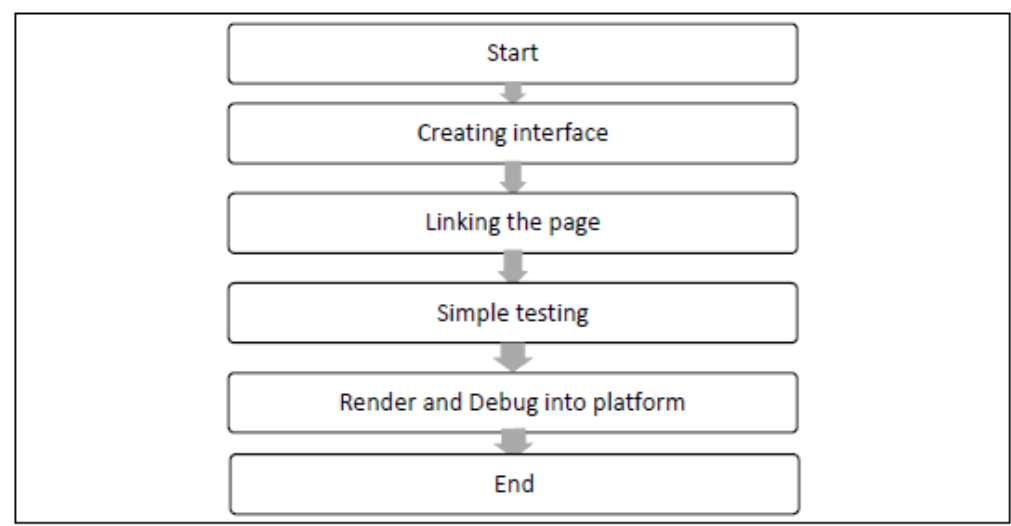

Figure 2. System process flow

\section{Coding, Testing, and System Design}

Coding, testing, system design and implementation can be combined as one stage which is the development of the mobile application system. The system contains three parts and functions. The first and foremost is the life insurance information details. This part contains all about life insurance that is needed by the young adults such as what is life insurance, which life insurance plan is best to fulfil one's needs, when is the time to use or claim life insurance, how to apply for life insurance and where to find life insurance agents. The next part is a calculator to calculate the range of life insurance coverage users should take. The last function is the frequently asked questions (FAQ). Most questions related to life insurance will be displayed here. Figure 3 shows the information structure of the suggested life insurance mobile application.

\section{Implementation}

Upon completion of the system, it will be implemented on an Android device as the mobile application's first prototype. The bar of minimum requirements for the system will be set as low as possible. The Android platform version is set to android 4.2 (JellyBean). The main reason this version is selected is that most mobile devices in Malaysia can be upgraded to JellyBean on the purchase as it has a $96 \%$ cumulative distribution. This can give everyone the opportunity to use the mobile application although their mobile devices may not be among the highend devices.

\section{Evaluation}

Lastly, an evaluation will be conducted to evaluate the life insurance mobile application. The evaluation is executed using the cooperative evaluation method. Cooperative evaluation is a method or process to collect feedback from users regarding the system to find problems.

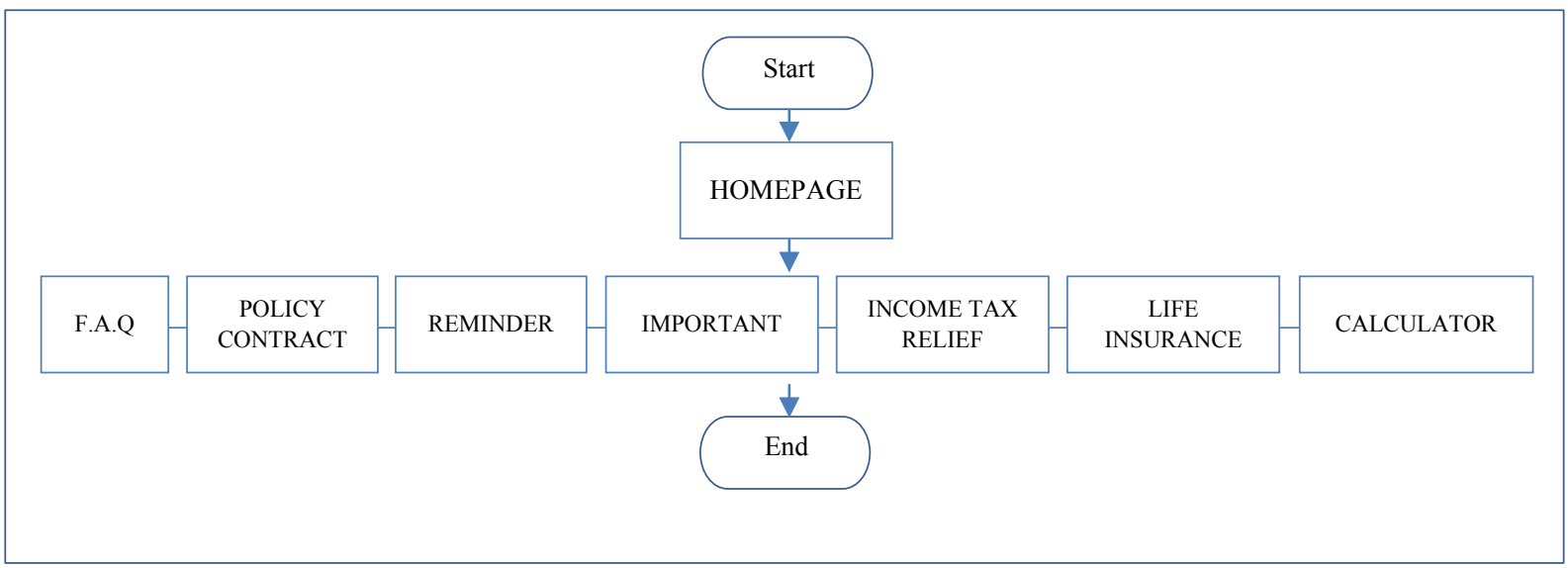

Figure 3. The structure of the mobile application upon completion 


\section{RESULTS}

\section{Life Insurance Mobile Application}

The first and foremost visual display that the user will see when they open the mobile application is the homepage screen or main menu. This page connects every sub-function and sub-section available in the mobile application, namely knowledge of life insurance and life insurance calculator. Figure 4 shows the homepage of the mobile application life insurance knowledge section on the Android device. Another part of the life insurance knowledge section is the FAQ section, this part consists of all questions that are usually asked by clients. The system displayed each question with its respective answer sorted from the most asked question with the highest frequency of the most asked questions to the lowest frequency.

The life insurance calculator has been included in the system. The system calculates the recommended life insurance plan that users should buy. The calculator is divided into three parts: current income, liabilities and income replacement. In the current income section, the system collects input from users focusing on their income revenue. This includes their current savings, investments and existing coverage in case the user is already under any health insurance program held by their employer or others. The system will then calculate the total value of that three values, giving the value of total income. Figure 5 shows the interface of the life insurance mobile application calculator section for the user's current savings and the liabilities and expected expenses. The system will ask the user about their desired replacement income. This includes the user's current annual income, the number of years for the user to replace their income, the user's survivors desired income after user can no longer work and the duration for those survivors to obtain money aid. Finally, the system will calculate the suggested instant savings users should have in case they were involved in accidents. This value also indicates the plan that is suitable for users.

\section{Life Insurance Mobile Application Evaluation}

Five participants will be randomly selected for this evaluation. There are several criteria to be fulfilled in the selection of participants. The first and foremost is that participants must be in the age range between 20 to 25 years old. The participants should not have any knowledge on life insurance, and earn a monthly income (i.e., salary). Each participant will be asked to complete the same set of tasks in a specific time frame. After completing the task, the participants will be asked about their opinions on the life insurance mobile application. The common question asked are as follows; "How do you feel when you see this page?" and "Do you have any questions when you finish reading this page?". This is to ensure that the participants would always provide enough feedback. As this research promise anonymity to the participants, the gender will be considered as neutral and will be referred as "the participant" in this study.
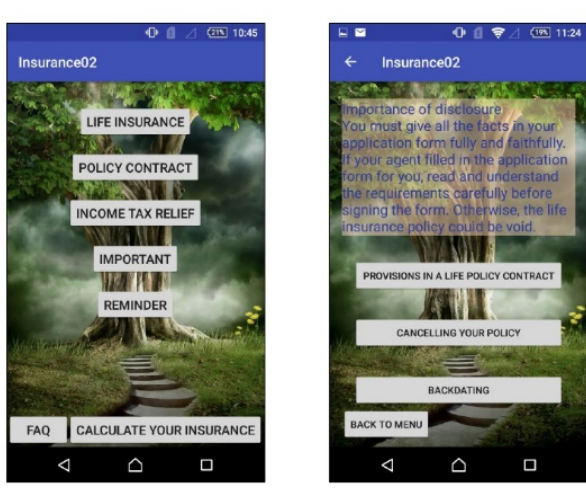

Figure 4. Homepage and content of the mobile application
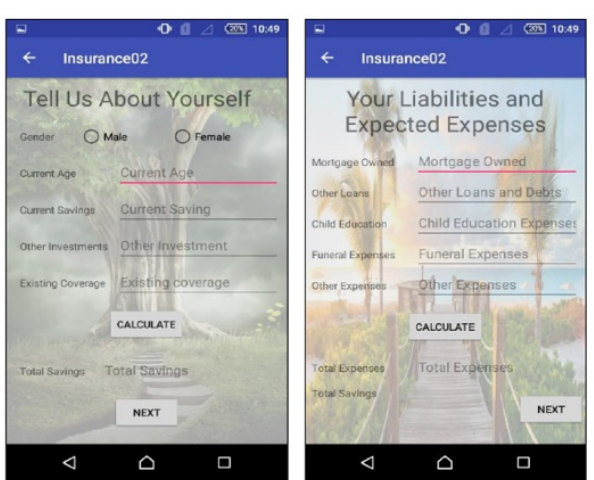

Figure 5. The interface of the life insurance mobile application calculator

User testing with participant 1. For the first user, the participant claims that the mobile application is easy to understand. The terms and information in it is very simple and understandable. The participant also said that the design is catchy to the eye due to the image of the background, the colour, and size of the font presented in the mobile application. Upon finishing using the mobile application, the participant suggested that the mobile application should be created in bilingual or provide a glossary for the user who may not understand the language. The participant also suggested creating more interactable functions between the user and the mobile application. 
User testing with participant 2. For the second user, the participant claims the knowledge in the mobile application is easy to understand. The participant suggested that the background of the mobile application and the font colour need to be changed as the current design is glaring to the participant's eyes.

User testing with participant 3. For the third user, the participant could not understand the questions given in the calculator, this is due to some unclear terms stated in the calculator such as "existing coverage" which means existing life insurance coverage. The participants also complained that the background is unsuitable for the theme of life insurance and asked to change the colour of the font to be darker.

User testing with participant 4. For the fourth user, the participant was confused with some terms in the mobile application such as the annual or monthly terms used in the calculator. The participant thought that the question asked for monthly salary, but the question was asking for the annual salary. The user also did not know what the activity flow for this mobile application was when starting it as there was no arrow or indicators where to click first. For the design of the mobile application, the participant suggested using only one background instead of two. The participant agrees that the background is already suitable but preferably to be consistent with only one background. The participant also suggested using a darker font if the background is lighter.

User testing with participant 5. For the fifth user, the participant does not see the flow of the application. The participant suggested that the mobile application should provide arrows or numbers for the users to know where to focus first. Next, the participant is confused with the back-button function. The participant thought that the back button provided in the mobile application is different from the back button provided by the smartphone itself. The participant suggested that the mobile application to be designed with easy terms such as the problem with the "monthly or annual salary", the participant suggested that the terms should always use the easy term which is 'monthly' so the user does not have to think hard how much their annual salary is. The participant also suggests creating a page with a narrower choice which can be seen in the 'Policy Contract' section of the mobile application, the list of policy contract provided is displayed on one page. The participant suggested that the first page should only provide the name of the policy contract which will bring the user to a specific page explaining the policy contract. The participant also complained of not knowing the progress of the mobile application as there is no title for each page.

\section{DISCUSSION AND CONCLUSION}

\section{Discussion}

To create awareness among young adults on the importance of life insurance in their daily life, a mobile application which impart knowledge of life insurance is created. Statistics suggest that a majority of young adults today do not have a life insurance plan. Although there are multiple websites that provide guidance on how life insurance work, the content is still too general. This mobile application aspires to overcome that problem by imparting knowledge of life insurance to help young adults understand how life insurance works generally. This is especially pertinent as handphones have become popular and almost everyone owns a handphone.

The creation of this mobile application was based on a waterfall lifecycle which included the initial investigation, requirements definition, coding and testing, system design, implementation, and evaluation. To ensure that awareness of the need of life insurance is highlighted among young adults, the content of the mobile application contain knowledge of life insurance including the type of policy contract, tax relief, and life insurance calculator. The calculator function is important feature as today's young adults could not see why they need to purchase life insurance. So, by using the life insurance calculator it will give the user a simple view on how much they should have in their savings to protect their love ones. The evaluation of this mobile application was also conducted among five participants using cooperative evaluation where two participants liked the mobile application and three participants gave some comments on the design of the mobile application.

\section{Conclusion}

The aim of this study is to create a life insurance mobile application to help equip young adults with knowledge of life insurance and its contents. The appropriate apps development tool is also selected which is Android Studio which implement the APK file and is debugged on an Android Operating System. This life insurance mobile application is created with a repetitive technique to assist young adults and connect them with life insurance, the knowledge of life insurance and the suggested life insurance plan. Lastly, a cooperative evaluation method is applied to evaluate the life insurance mobile application. 


\section{Future Study}

Future studies are expected to help improve the life insurance mobile application by creating the mobile application in bilingual with assistance in the glossary. The design of the interface of the mobile application also needs to be reconstructed as some users do not like the colour and the background image. The terms and language of the mobile application also need to be refined to give clearer terms to the users. Lastly, the mobile application is expected to be developed on the Intelligent Operating System (IOS) to expand the user coverage.

\section{REFERENCES}

Barnett, J. C., \& Vornovitsky, M. S. (2016). Health insurance coverage in the United States: 2015. Washington, DC: US Government Printing Office.

Cafarella, R. (2001). Developing effective learning programs for adults. APC Monographs, 5.

Flood, D., Harrison, R., Iacob, C., \& Duce, D. (2012). Evaluating mobile applications: a spreadsheet case study. International Journal of Mobile Human Computer Interaction (IJMHCI), 4(4), 37-65.

Gebauer, J., Tang, Y., \& Baimai, C. (2008). User requirements of mobile technology: results from a content analysis of user reviews. Information Systems and e-Business Management, 6(4), 361-384.

Huang, K. Y. (2009, October 20-22). Challenges in Human-Computer Interaction Design for Mobile Devices. World Congress on Engineering and Computer Science 2009. Retrieved from http://www.iaeng.org/ publication/WCECS2009/WCECS2009 pp236-241.pdf

Ionescu, O. C. (2012). Life insurance-Their characteristics importance and actuality on the Romanian market. Scientific Board Members, 17.

Lant, K. (2018, February 15). The Complete Guide to Life Insurance. Retrieved from The Simple Dollar: https://www.thesimpledollar.com/life-insurance-guide/

Marquand, B. (2012, January 2). Ask the Life Insurance Expert. Retrieved from Insure.com: https://www.insure.com/life-insurance-faq/leftover-cash-value-life-insurance.html

Moumane, K., Idri, A., \& Abran, A. (2016). Usability evaluation of mobile applications using ISO 9241 and ISO 25062 standards. SpringerPlus, 5(1), 548.

Sambasivan, D., John, N., Udayakumar, S., \& Gupta, R. (2011, November). Generic framework for mobile application development. In Internet (AH-ICI), 2011 Second Asian Himalayas International Conference on (pp. 1-5). IEEE.

Stephanidis, C., Akoumianakis, D., Sfyrakis, M., \& Paramythis, A. (1998, October). Universal accessibility in HCI: Process-oriented design guidelines and tool requirements. In Proceedings of the 4th ERCIM Workshop on User Interfaces for all, Stockholm, Sweden (pp. 19-21).

Treser, M. (2015, August 16). Getting To Know ADDIE: Part 1 - Analysis. Retrieved from eLearning Industry: https://elearningindustry.com/getting-know-addie-analysis

Whitehurst, G. J. (2017, March 9). Why the federal government should subsidize childcare and how to pay for it. Retrieved from Brookings report: https://www.brookings.edu/research/why-the-federal-government-shouldsubsidize-childcare-and-how-to-pay-for-it/ 